\title{
First in Poland, unique 60-mm long single drug eluting tapered stent implantation in a patient with unstable angina
}

\author{
Pierwsza w Polsce implantacja 60-mm taperowanego stentu u pacjenta \\ z niestabilną dławicą piersiową
}

\author{
Jakub Podolec, Łukasz Niewiara, Jakub Baran, Piotr Pieniążek, Krzysztof Żmudka \\ Interventional Cardiology Clinic, Jagiellonian University, Medical College, John Paul II Hospital, Krakow, Poland
}

Coronary artery disease is still a disease with high morbidity and mortality rates. Technology development is one of the most important factors among treatment methods and provides a personalised approach to patients. A 66-year-old patient was admitted to the Interventional Cardiology Clinic with symptoms of unstable angina, recently progressing up to class III according to Canadian Cardiovascular Society classification. The patient was diagnosed and treated for arterial hypertension and dyslipidaemia, without other significant comorbidities. Three weeks earlier the patient underwent coronary angiography, which revealed a single, long lesion in the left anterior descending (LAD). After Heart Team consultation a single coronary artery by-pass graft $(C A B G)$ to the LAD was proposed as the best treatment option. The patient did not agree to undergo CABG and was re-qualified to percutaneous coronary intervention. Coronary angiography confirmed critical long stenosis in the proximal/mid LAD (Fig. 1A, B). An extra back-up therapeutic catheter was introduced via the right femoral artery. A Ryiujin $1.25 / 10 \mathrm{~mm}$ balloon was used to cross and pre-dilate the proximal lesion. Then the lesion was treated with long inflations of a non-compliant 2.5/15 $\mathrm{mm}$ balloon with pressures up to $22 \mathrm{~atm}$. After intracoronary vascular ultrasound (IVUS) for artery size and plaque morphology estimation (Fig. 2A) a tapered sirolimus drug-eluting stent Meril, Biomime Morph, $60 \mathrm{~mm}$ long, with proximal $3.0 \mathrm{~mm}$ and distal $2.5 \mathrm{~mm}$ diameter was prepared for this patient. The stent was introduced and implanted with pressure of $10 \mathrm{~atm}$ without any complications. Post dilatation was performed with a $3.25 / 15 \mathrm{~mm}$ non-compliant balloon with $8 \mathrm{~atm}$ pressure in the distal and up to $24 \mathrm{~atm}$ in the mid and proximal parts of the stent. The guide wire was easily repositioned to a diagonal branch and the "kissing balloon" technique was applied to finalise the result (Fig. 3). Proper apposition of the stent was confirmed with IVUS (Fig. 2B). The patient was discharged. Long and complex lesions are becoming more common in patients presenting to interventional cardiology cath-labs. New, tapered, long drug-eluting stents are designed to cover the whole lesion and adjust to native vessel anatomy. A single-stent technique is favourable, avoiding the risk of sub-optimal apposition of overlapping stents, and after correct lesion preparation with non-compliant balloon it is easy and safe to introduce. We present a unique case of a very long 60-mm tapered stent implantation in a patient with unstable angina. The long term-results of long stent implantations still need to be assessed in clinical trials; however, our first experiences are promising.

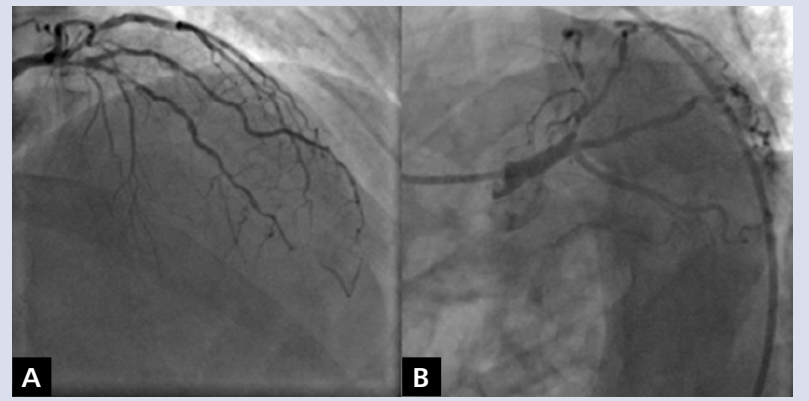

Figure 1. A, B. Left anterior descending lesion prior to percutaneous coronary intervention

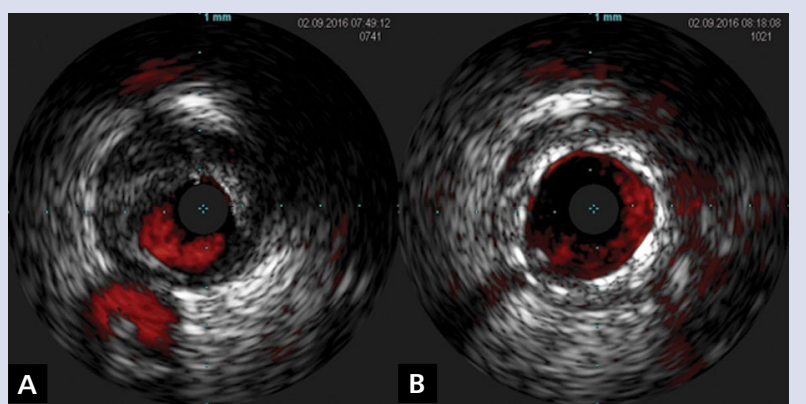

Figure 2. Intracoronary vascular ultrasound cross-sectional view of left anterior descending prior to (A) and after stent implantation (B)

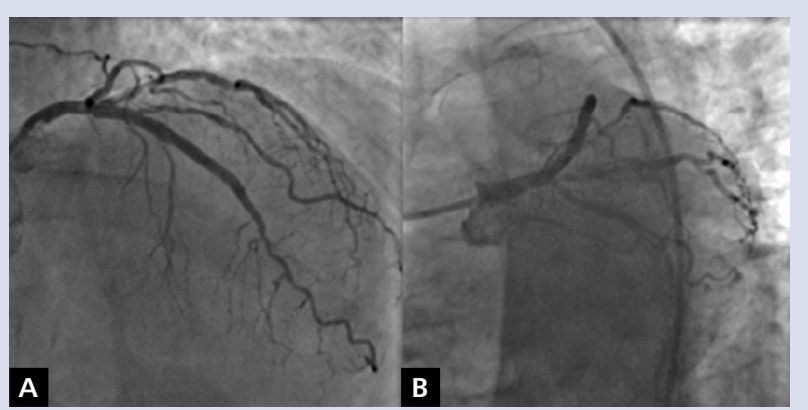

Figure 3. A, B. Left anterior descending after successful $60 \mathrm{~mm}, 3.0 / 2.5 \mathrm{~mm}$ tapered stent implantation

Address for correspondence:

Jakub Podolec, MD, PhD, Department of Interventional Cardiology, Jagiellonian University College of Medicine and the John Paul II Hospital, ul. Prądnicka 80, 31-702 Kraków, Poland, e-mail: jjpodolec@gmail.com

Conflict of interest: none declared

Kardiologia Polska Copyright (c) Polskie Towarzystwo Kardiologiczne 2017 